\title{
The role of lipids in corneal diseases and dystrophies: a systematic review
}

\author{
Tyler G. Rowsey ${ }^{1,2}$ and Dimitrios Karamichos ${ }^{2 *}$ (])
}

\begin{abstract}
Corneal diseases are an extensive cause of blindness worldwide and continue to persist as a challenging public health concern. Recently, various lipid-based therapies have been advocated for the modulation of corneal diseases; however, the number of studies is still very limited. Here we focus on developments and challenges on lipid-based therapies for dry eye disease, diabetic neuropathy, and Fuchs' endothelial corneal dystrophy. All three diseases are highly prevalent conditions and involve corneal stress and inflammation. Lipid-based therapeutics discussed includes cyclooxygenase inhibitors, essential fatty acids, and resolvin analogs. Lipids also show increasing promise as biomarkers of disease and are explored in this review.
\end{abstract}

Keywords: Corneal lipidomics, Lipid-based therapy, Corneal diseases

\section{Introduction}

\section{Cornea structure}

The cornea is composed of a clear, dome-shaped layer of tissue that provides transparency and light refraction to the eye [1-3]. The cornea, limbus, and bulbar and tarsal conjunctiva make up the ocular surface and function to protect the eye by providing the first line of defense against damage and infection [3, 4]. The cornea consists of five major layers including the epithelium, Bowman's Layer, stroma, Descemet's membrane, and endothelium (Fig. 1); it is approximately $500 \mu \mathrm{m}$ thick and accounts for two-thirds of the refractive power of the eye [5]. The cornea is one of the most sensitive areas in the body, highly innervated, with a nerve density that tends to be around 300-600 times higher than that of the skin [3]. The peripheral cornea has sensory nerve fibers that have a myelinated shell. The central cornea, which is innervated by the ophthalmic nerve, tends to be less sensitive along the vertical meridian and more sensitive along the horizontal meridian [6]. The arrangement of the collagen layers in the stroma and the regular arrangement of collagen

\footnotetext{
*Correspondence: dimitrios-karamichos@ouhsc.edu

2 Department of Ophthalmology/Dean McGee Eye Institute, University of Oklahoma Health Sciences Center, Oklahoma City, OK, USA Full list of author information is available at the end of the article
}

fibrils in the cornea are considered to be critical for the maintenance of corneal transparency [7].

\section{Damage to the cornea}

When injury or disease proceeds, it can lead to corneal opacities or even blindness through the disordering of the extracellular matrix [7]. The corneal endothelial monolayer of cells is the primary contributor to the maintenance of corneal transparency. When the barrier functions of the endothelium are compromised, it results in a loss of visual acuity $[8,9]$. Unfortunately, once there is damage to the cornea, it has proven to be complicated through countless studies to reverse this process.

Wound healing in the cornea is a diverse process involving many factors including cell death, migration, proliferation, differentiation, and extracellular matrix remodeling [10]. Similarities and differences are observed in the healing processes of corneal epithelium, stroma, and endothelium, as well as cell-specific alterations in each of the layers [10]. Damage to the cornea from diseases such as dry eye, corneal edema, diabetes mellitus, and dystrophies are prevalent conditions and often involve ocular surface stress and inflammation. One of the key features associated with these corneal diseases is oxidative stress [11]. Oxidative stress increases advanced glycation end product (AGE) accumulation 


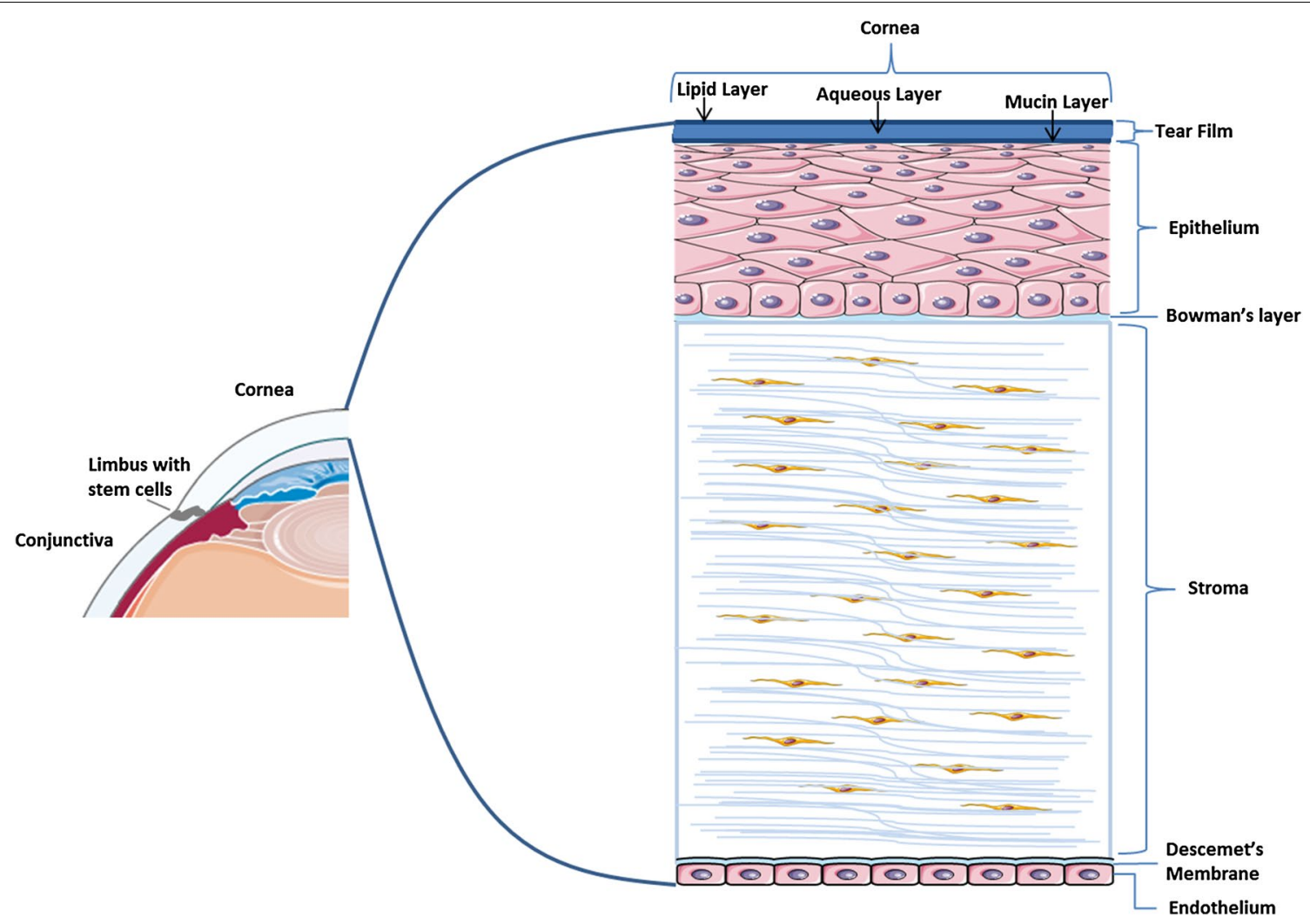

Fig. 1 Structure of the cornea. Some images were provided by servier medical images

and activation of Protein kinase $\mathrm{C}$ and the polyol pathway $[12,13]$. Chronic inflammation of the ocular surface is common among many diseases such as dry eye disease [14-17]. The inflammatory process within the cornea can cause substantial irreversible damage to the corneal as well as the conjunctival epithelia, with subsequent visual loss [18]. The damage to the cornea from these diseases are an extensive cause of blindness worldwide and continue to persist as a challenging public health concern [19].

\section{Current treatments and lipids}

The anatomical and physiological barriers that the cornea offers against the entrance of bacteria and other pathogens may also pose difficulties for the access and effectiveness of drugs. Current topical treatment options for ocular surface inflammation available today include mainly corticosteroid eye drops containing antibiotics, non-steroidal anti-inflammatory agents and cyclosporine A. Topical corticosteroids have shown through previous studies to have a rapid onset of action and efficacy when treating DED [20], but they have a limited range of effectiveness because of their potential side effects, which include posterior subscapsular cataract and increased intraocular pressure [21]. Other studies have found that these barriers may be overcome through the use of a variety of lipid based therapies.

Lipids are classified from a group of hydrophobic or amphiphilic small molecules composed of the carbanionbased condensation of thioester or isoprene groups; they include fatty acids, glycerololipids, sphingolipids, and sterols [22]. Lipids execute a variety of biological functions including cell signaling, energy storage, and maintenance of compartmental boundaries. In this review, we highlight the most recent developments in lipid-based therapies to modulate ocular surface inflammation as well as the potential for lipid-based molecules as a biomarker of disease in multiple ocular dysfunctions including DED, diabetic retinopathy, and Fuchs' endothelial corneal dystrophy (FECD) (Table 1). Recent research has revealed the potential use of lipid therapeutics for the improvement of corneal damage due to dystrophies and disease.

\section{Dry eye disease}

Dry eye disease refers to a condition in which the individual does not produce enough quality tears to lubricate and nourish the eye [23]. Tears are needed to maintain 
Table 1 Lipid therapeutics/biomarkers available for corneal diseases

\begin{tabular}{|c|c|}
\hline Disease & Lipid therapeutics/biomarkers \\
\hline Dry eye disease [17] & $\begin{array}{l}\text { Eicosapentaenoic acid, docosahexaenoic acid, and alpha linolenic acid, and resolvins have shown promise in } \\
\text { improving symptoms of DED, matrix metalloproteinase-9 as an ideal biomarker due to its involvement in } \\
\text { ocular surface inflammation }\end{array}$ \\
\hline Diabetic neuropathy & $\begin{array}{l}\text { Menhaden oil, daily injections of resolvin-D1, salsalate, enalapril, neuroprotectin D1, docosahexaenoic acid, } \\
\text { as well as combination of enalapril, a-lipoic acid and menhaden oil have all shown to improve diabetic } \\
\text { neuropathy }\end{array}$ \\
\hline Fuchs' endothelial corneal dystrophy & $\begin{array}{l}\text { Mefenamic acid and nimesulide have shown to improve oxidative stress, ROCK inhibitor show potential for } \\
\text { regenerative medicine, Diacylglycerophosphocholines, 1-ether, 2-acylglycerophosphocholines, eight sphin- } \\
\text { gomyelins, and up to two long-chain highly unsaturated cholesteryl esters increased in the AH of FECD } \\
\text { eyes, indicating potential oxidative stress markers }\end{array}$ \\
\hline
\end{tabular}

the health of the front surface of the eye and also to allow clear vision. DED is a complicated disease of the ocular surface, which includes any of the following symptoms: visual disturbances, eye discomforts, and dryness due to tear film instability [24]. Pathogenesis for DED includes increased osmolarity of the tear film and inflammation of ocular surfaces and lacrimal glands [25]. It is clinically characterized into two separate subtypes: hyperevaporative DED with increased tear evaporation and aqueousdeficient DED with decreased tear secretion [26]. It can lead to visual loss, damage to the ocular surface, discomfort and overall reduction in the quality of life [25].

Due to the significant role meibomian glands play in providing lipids to the tear film, meibomian gland dysfunction (MGD) is one of the leading causes of DED [27]. A decrease in MGD leads to an increase in the evaporation of tears from the ocular surface [28]. Meibum is secreted by the Meibomian gland, and it is a predominant source of lipids that are important for the maintenance of tear film stability [29]. DED is a common and often chronic problem, particularly in older adults. There are numerous new therapeutic approaches that are under development, including anti-inflammatory agents, secretory stimulants, and tear film stabilizers; as a result, as improved endpoints are incorporated into clinical trials, it is likely that multiple therapeutic agents will emerge in the foreseeable future [4]. One recently approved lipid based molecule for the treatment of DED is lifitegrast; it exerts its mechanism of action by preventing LFA-1/ ICAM-1 from interacting which prevents $T$ cell activation and recruitment [30]. This drug was approved for the treatment of DED in 2016 due to its excellent therapeutic efficacy as ophthalmic drops and its rapid onset of action [30].

\section{Omega-6 linolenic acid/omega-3 fatty acids}

Artificial tears provide temporary symptomatic relief and are the most common therapy for DED, but they do not address any of the underlying pathogenic mechanisms that lead to DED. Inflammation plays a contributing role in the pathogenesis of DED, indicating the vast importance of lipid-based therapies to reduce inflammation of the ocular surface.

There are three $\omega-3$ fatty acids that cannot be synthesized in the body and must therefore be supplemented in the diet; these include eicosapentaenoic acid (EPA), docosahexaenoic acid (DHA), and alpha linolenic acid (ALA) [31]. Prostaglandin metabolism is modulated through EPA and DHA through an anti-inflammatory prostaglandin synthesis due to the competitive inhibition of the arachidonic acid pathway [32]. Supplementation of $\omega-3$ prevents the creation of any new $\omega-6$ prostaglandin precursors, which in turn inhibits apoptosis of the secretory epithelial cells in the lacrimal gland and helps clear meibomitis; this allows for a healthier lipid layer to protect the cornea and tear film [33]. ALA is a polyunsaturated fatty acid (PUFA) that has shown the potential to improve dry eye symptoms through a dietary supplement due to its anti-inflammatory effects [34-36]. An in vivo study showed that n-3 PUFA has several mechanisms that contribute to its anti-inflammatory effects through inhibition of nuclear factor kappa $\mathrm{B}(\mathrm{NF}-\mathrm{k} \beta$ ) activation in an animal inflammation model as well as through regulation of eicosanoid metabolism [37]. Recent studies have also shown that the ocular surface epithelia and tears of patients with DED, as well as in many animal models have an enhanced expression of pro-inflammatory mediators which include adhesion molecules, protein matrix metalloproteinases, cytokines, and chemokines [38, 39]. DED patients, as well as those who suffer from Sjogren's syndrome have also been found to have an increased production and activation of interleukin-1 $\beta$ (IL-1 $\beta$ ), interleukin-6 (IL-6), interleukin-8 (IL-8), tumor-necrosis factor- $\alpha$ (TNF- $\alpha$ ), and transforming-growth factor- $\beta$ (TGF- $\beta$ ), indicating the significant therapeutic implications of treatment with ALA [40]. Interleukin- $1 \alpha$ (IL- $1 \alpha)$ is able to up-regulate TNF- $\alpha$ release as well as its own autocrine production 
[41]. TNF- $\alpha$ has been described as a key mediator in the pathogenesis of DED [42]. ALA treatment was shown to be an effective treatment for decreasing the corneal and conjunctival expression of IL- $1 \alpha$ and TNF- $\alpha$ [43]. Rashid et al. also revealed that the treatment of ALA caused a nearly 100-fold increase in expression of interleukin-10 (IL-10) in dry eye conjunctiva [43]. IL-10 is produced by activated machophages and lymphocytes, and it acts to inhibit IL-1 and TNF production, which further contributes to the down-regulation of inflammation [43]. The PUFA pathways for $n-3$ and n- $6 \omega$-fatty acids competitively utilize the same enzymes [44]. Topical ALA treatment led to significant decrease in dry eye signs and inflammatory changes at both cellular and molecular levels [43]. Findings demonstrated that $\omega-3$ and $\omega-6$ can act directly on immortalized human Meibomian gland epithelial cells to have positive impacts on the quality and quantity of intracellular lipids [31].

\section{In vivo studies}

In order to demonstrate that an oral supplementation of $\omega-3$ fatty acids, antioxidants, and vitamins improves dry eye symptoms, a large study was conducted to determine the effects of this treatment. One study population, which consisted of 1419 patients, included $74 \%$ women with a median age of 58.9 years showed dietary supplementation with $\omega-3$ essential fatty acids, antioxidants, vitamins, and minerals were useful to improve dry eye symptoms [45]. To relieve ocular surface dysfunction associated with DED, these patients used artificial tears as well as attended routine daily practice [45]. Other positive effects shown in this study included a decrease in the use of artificial tears, reduced conjunctival hyperemia, and improvement in tear secretion and tear film stability (Table 2) [45].

Epitropoulos et al. sought out to assess the effect of oral re-esterified $\omega-3$ fatty acids on tear osmolarity, matrix metalloproteinase-9 (MMP-9), tear break-up time (TBUT), Ocular Surface Disease Index, fluorescein corneal staining, Schirmer score, MGD stage and $\omega-3$ index in subjects with dry eyes and confirmed MGD (Table 2) [46]. The mean of 105 subjects who completed the study were $56.8 \pm 17.0$ years, of which $51 \%$ were randomized to the $\omega-3$ group and $49 \%$ to the control group with $71.4 \%$ of the group being females [46]. Tear osmolarity plays a key role in determining the severity of DED; as a result, there was a significant reduction in osmolarity within this study at 12 weeks $(P=0.004)$ [46]. This study showed significant improvement in the TBUT scores and a significant reduction in subjects testing positive for MMP-9 bioenzyme in the tear film, which are both correlated with an improvement in DED [46]. An improvement in the TBUT scores indicates that the dietary supplementation with the $\omega-3$ fatty acids improves the inherent stability of the tear film [46].

Sambursky and co-authors conducted a retrospective single center medical chart review of 100 patients that determined the effectiveness of using MMP-9, which is induced by key cytokines in the early stages of the inflammatory cascade, as an ideal biomarker because its elevation confirms the presence of clinically significant ocular surface inflammation [31]. MMP-9 is characterized as a proteolytic enzyme produced by stressed epithelial cells on the ocular surface in DED, which is elevated throughout the progression of DED $[47,48]$.

Malhotra et al. conducted a study that involved 60 patients with moderate MGD that were divided into a treatment group, composed of seventeen females and thirteen males aged $53.3 \pm 6.9$ years that received an oral supplementation of a triglyceride formulation of $\omega-3$ fatty acids (FAs) and a control group, composed of eleven females and nineteen males aged $53.6 \pm 8.7$ years [49]. Artificial tear substitutes and eyelid hygiene was given to each group, which consisted of warm compressers and lid massage once daily for a period of 12 weeks (Table 2) [49]. Multiple improvements were noted including photopic and scotopic contrast sensitivity, tear film stability represented by the prolongation of the TBUT from baseline, an increase in tear secretion noted by the increased value of Schirmer score, and an improvement in ocular surface staining over the duration of the study from baseline to 12 weeks [49]. Deinema and co-authors revealed through a randomized, double-masked, placebo-controlled clinical trial with 54 participants that a moderate daily dose of krill oil $(945 \mathrm{mg} /$ day EPA, $+510 \mathrm{mg} /$ day DHA) and fish oil (1000 mg/day EPA + $500 \mathrm{mg} /$ day DHA) for 3 months, resulted in improved symptoms in individuals with DED, including reduced tear osmolarity and increased tear stability (Table 2) [50].

\section{In vitro studies}

Recent research has also indicated promising results through experiments performed in vitro through the use of human corneal epithelial [51] cells.

Erdinest and co-authors determined the anti-inflammatory effects of systemic PUFAs on HCE cells in vitro [52]. Studies revealed that topical anti-inflammatory therapies inhibit the various inflammatory mediators and reduce the signs and symptoms of DED [52]. Topical corticosteroids show efficacy in treating dry eye associated inflammation, and have a rapid onset of action [20]. In this study, cells were treated with inflammation inducers such as lipopolysaccharide (LPS) and LPS binding protein or with polyriboinosinic: polyribocytidylic acids at a dose of $25 \mu \mathrm{g} / \mathrm{mL}$ [52]. ALA dramatically reduced the poly I:C and LPS complex stimulated production of the 


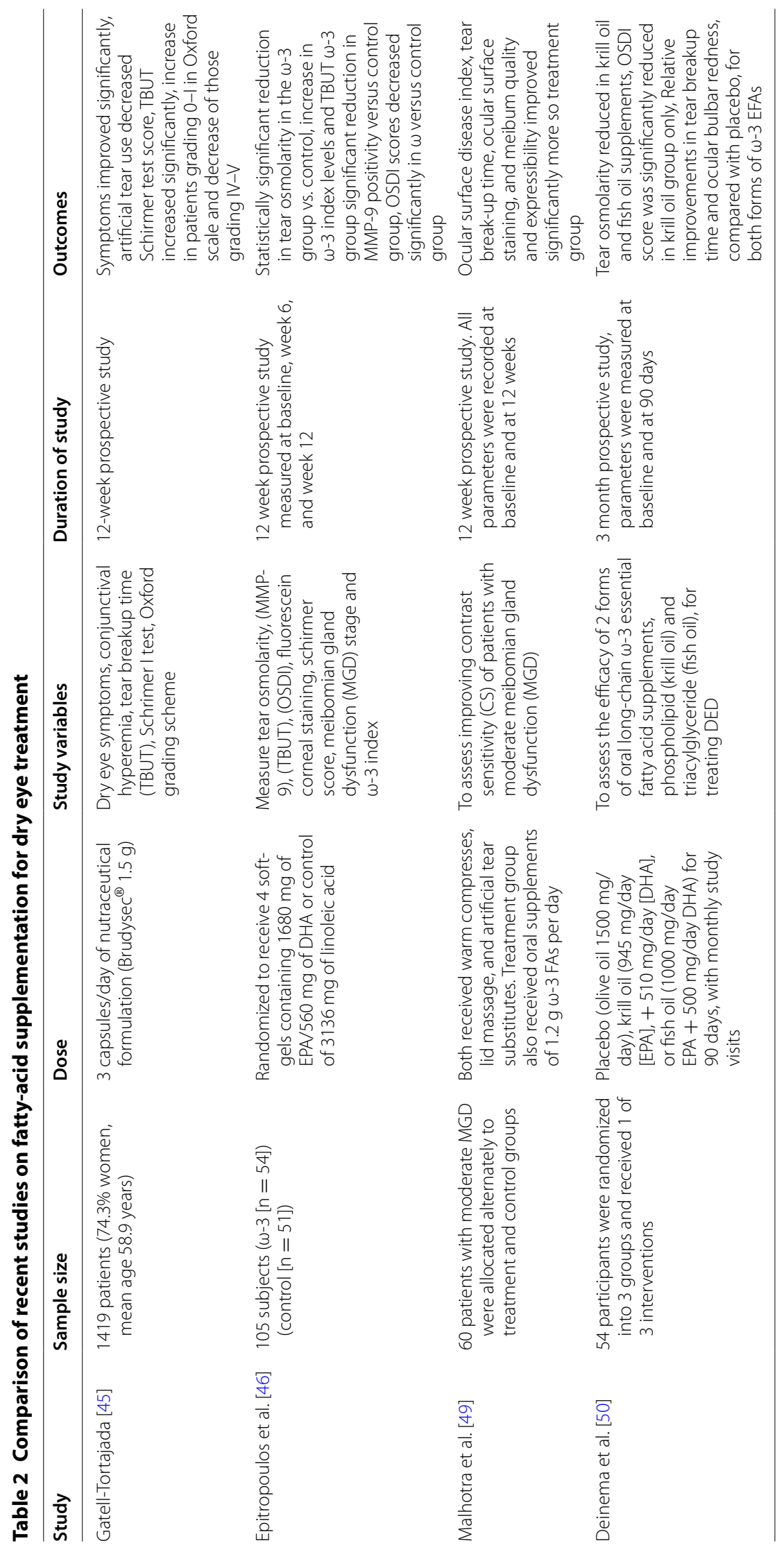


pro-inflammatory cytokines TNF- $\alpha$, IL-6, interleukin- $1 \beta$ (IL-1 $\beta$ ), and the chemokine interleukin-8 (IL-8) in cultured HCE cells, specifically a dose-dependent reduction was demonstrated by ALA for all of these anti-inflammatory mediators [52]. ALA showed inhibitory effects on the protein secretion of the inflammatory mediators [52], and it also demonstrated a decrease in nuclear factor of kappa light polypeptide gene enhancer in B-cells inhibitor, alpha (Iк $\beta \alpha)$ mRNA expression, suggesting the antiinflammatory effects of ALA involve regulatory effects of the NF- $\mathrm{k} \beta$ pathway [52].

In the PUFAs family, there have been four new groups of pro-resolution mediators that have been identified which include lipoxins, protectins, maresins and resolvins (RVs) [18]. RVs are endogenous, potent, local acting molecules classified as non-classical Eicosanoids $[18,53]$. RVs can be formed through metabolizing the compounds EPA and DHA $[18,54]$. The E-series RVs are formed when EPA is metabolized first by cyclooxygenase- 2 or the cytochromeP450 pathway in vascular endothelial cells, and then by neutrophil 5-lipooxygenase [54]. Since inflammation plays a crucial role in the pathogenesis of DED, RVs could have significant therapeutic implications. Erdinest et al. looked at the efficacy of RV-D1 treatment in HCE cells in vitro after stimulation with poly I:C [55]. Results indicated a highly potent anti-inflammatory effect of RV-D1 on HCE cells in vitro [55]. RV-D1 significantly reduced the Poly $\mathrm{I}: \mathrm{C}$ inflammatory reaction and dramatically reduced the production of the pro-inflammatory cytokines TNF- $\alpha$, IL-6, IL-1 $\beta$ and IL-8 in cultured HCE cells [55]. A significant dose-dependent reduction was demonstrated by RV-D1 for TNF- $\alpha$ and IL-1 $\beta$ [55]. RV-D1 demonstrated inhibitory effects on the protein production of the inflammatory mediators [55]. Furthermore, the HCE cells stimulated by Poly I:C and treated with RV-D1 demonstrated a decrease in $I \kappa \beta \alpha$ mRNA expression, suggesting that the anti-inflammatory effects of RV-D1 involve regulatory effects of the NF-kB pathway [55].

\section{Future directions and challenges for dry eye disease}

Dry eye disease is a relatively common condition in which the individual does not produce enough quality tears to lubricate and nourish the eye. Despite recent advances, advances in ocular surface lipid research for DED have been slow going due to numerous unanswered questions regarding the role of lipids. Once the lipidomic profiles of this disease has been characterized, it will provide vital answers to how lipid-based therapies are incorporated into overall anti-inflammatory strategies for the ocular surface. Furthermore, there are still limited options for lipid-based anti-inflammatory therapy. In the future, advances in identifying and quantifying lipids throughout this disease will provide a better understanding of ocular surface inflammation and allow clinicians to provide better treatments for DED.

\section{Diabetes mellitus}

Diabetes mellitus (DM) is a common metabolic disease characterized as a hyperglycemic condition [56, 57]. In the United States, it is an epidemic disease where approximately 6.2 million people are underdiagnosed [56]. DM is separated into two main categories: type 1DM (T1DM) and type 2DM (T2DM). T1DM, or insulin dependent diabetes, is due to the autoimmune destruction of the $\beta$-cells in the pancreas $[58,59]$. A prolonged excessive elevated blood glucose level that eventually leads to insulin resistance leads to T2DM, or non-insulin dependent diabetes $[58,59]$. T2DM is the most prevalent in the United States, and it has seen significant rises in prevalence over the past thirty years.

The cornea suffers from a substantial amount of changes and injuries in DM due to reduced corneal sensitivity, increased corneal thickness, susceptibility to corneal trauma, persistent epithelial defects, corneal epithelial damage, recurrent corneal erosions, and alteration in tear quality and quantity [57,60]. A severe complication of diabetes and leading cause of preventable blindness is diabetic peripheral neuropathy (DPN). DPN is a well-known microvascular complication of T2DM which leads to further infections and increases the risk of mortality; it occurs in a considerable amount of diabetic patients [61, 62]. As DM continues to become more prevalent across the world, the number of people at risk for developing DPN continues to increase. DM has a substantial effect on the ocular tissues even when it is well managed, which contributes to the disease severity when concerning the cornea. The major pathogenic factor of DM is hyperglycemia, which is a significant contributor to the accumulation of AGEs [13, 63]. Diabetic retinopathy is the most common ocular complication of diabetes, but there are many others including corneal dysfunction, cataracts, glaucoma, neuropathy, ischemic optic neuropathy, and diabetic macular edema $[64,65]$.

Many attempts with approved treatments have failed in clinical trials to slow progression or inhibit all of the complications associated with corneal DM. Recent studies have suggested the possibility of using lipid-based therapies to provide benefit to patients suffering from DPN, and research plays a key role in discovering novel treatments for these individuals. Recent advances in the use of lipids as novel therapeutics are discussed.

\section{Novel lipid-based therapeutics to treat diabetic neuropathy}

Recent studies have determined one beneficial treatment for DPN is dietary enrichment with $n-3$ fatty acids. 
Coppey and co-authors used a rat model for T1DM with a dietary enrichment of menhaden oil, a natural source of n-3 fatty acids, that prevented and reversed multiple pathological endpoints associated with DPN [66]. Former studies have demonstrated that DM can cause the production and accumulation of free oxygen radicals, key factors contributing to the early development of DPN [67].

Corneal nerves in the subepithelial layer and epithelium are significantly decreased in diabetic rats indicating an excessive amount of damage to the nerve fibers [66]. However, upon treatment with a diet enriched with menhaden oil, a prevention and/or reversal in the loss of corneal nerves was observed in these diabetic rats indicating potential therapeutic benefits for this molecule [66]. Menhaden oil is used as a source of $\omega-3(n-3)$ polyunsaturated fatty acids, enriched in EPA and DHA as a dietary supplement for human consumption [68]. Upon onset of hyperglycemia and the development of diabetic complications related to neuropathy, Shevalye et al. has shown that treatment of a mouse model suffering from T2DM with a dietary supplement of menhaden oil or daily injections of RV-D1 reverses neuropathic deficits [68]. This includes the slowing of nerve conduction velocity and decreased progression of loss of sensitivity and/or density of nerves in the skin, cornea, and retina [68]. RvE1 is also a potential anti-inflammatory therapy for patients with corneal inflammation [69].

Another potential treatment to patients suffering from DPN is the use of anti-inflammatory compounds such as salsalate [70]. Salsalate, a prodrug of salicylate that allows for better oral absorption, establishes its primary mechanism of action as a nonsteroidal anti-inflammatory which functions to inhibit the synthesis of prostaglandins through the inactivation of cyclooxygenase enzymes [71]. Research has indicated the usefulness of enalapril, an angiotensin converting enzyme inhibitor and $\alpha$-lipoic acid, an antioxidant, in their ability to individually partially improve DPN [72]. More recent studies have indicated that the combination of enalapril, $\alpha$-lipoic acid and menhaden oil treatment was able to fully reverse the neuropathic endpoints except for motor nerve conduction velocity [72].

\section{Lipid-mediated corneal neuroprotection}

Docosahexaenoic acid is necessary for a multitude of functions in the body including memory formation, neuroprotection, synaptic function, as well as brain and retina development; it is involved in several processes, including photoreceptor biogenesis and function, excitable membranes functions, and photoreceptor biogenesis and function [73-80]. The importance of these (n-3) fatty acids in vision has been established through recent studies. One of the more characterized members of this family include neuroprotectin D1 (NPD1), which exhibits many beneficial effects throughout other parts of the body including reactive oxygen species (ROS) production and cyclooxygenase activities in human neutrophils [8183]. Due to the anti-inflammatory effects it has shown in various parts of the body, it has been speculated for the potential use as a neuroprotectin within the cornea.

Docosahexaenoic acid is the precursor to the lipid mediator NPD1, which has shown to have potent antiinflammatory actions [84, 85]. However, specialized pro-resolving mediators such as DHA and NPD1 have shown the ability to resolve inflammation without the mechanism of immune suppression, indicating the use of the term immunoresolvents [86, 87]. Recent studies have shown that corneas treated with DHA along with pigment epithelial-derived factor exhibit an increase in NPD1 synthesis, indicating the potential use of NPD1 as an effective treatment for neurotrophic corneas [18, 88]. An early inflammatory response is key for corneal wound healing, but it must be resolved to see proper tissue homeostasis [89]; as a result, Cortina et al. has indicated the effect of NPD1 on corneal nerves may be due to an injury to the cornea, leading to modulation of the inflammatory response, which leads to corneal epithelial cell survival [88]. These neuroprotectins offer interesting options for novel therapeutics in the treatment of DPN and other diseases involving corneal nerve damage.

\section{Future directions and challenges for diabetes mellitus}

Corneal defects have been reported in both T1DM and T2DM patients, but the literature is currently lacking exact pathophysiological differences. DM involves increased corneal thickness [90, 91], reduced corneal sensitivity, corneal epithelial lesions [92, 93], delayed wound healing capacity and repair mechanisms [94, 95], and weakening of the epithelial barrier [96] leading to corneal infections and stromal fibrosis $[97,98]$.

Recent studies have shown that there are several metabolites that are differentially regulated in both T1DM and T2DM constructs when compared to human corneal fibroblasts (HCFs) as well as significant differences in mitochondrial structure in both T1DM and T2DMs, as compared to HCFs, when allowed to secrete and assembly their own extracellular matrix [60]. Future studies are needed to investigate the molecular mechanisms of human diabetic keratopathy in order to better understand corneal stromal defects due to DM and develop novel therapeutics to treat diabetic keratopathy defects.

\section{Fuchs' endothelial corneal dystrophy}

Fuchs' endothelial corneal dystrophy (FECD) is a relatively frequent degenerative corneal condition confined to the corneal endothelium, characterized by subsequent 
changes in cell morphology, as well as deposits of collagen in the Descemet membrane, apoptosis, [99-101] and endothelial cell loss that is inherited in an autosomal dominant pattern with $100 \%$ penetrance with variable expressivity [102, 103]. FECD is estimated to affect approximately $4 \%$ of Americans older than 40 years old, but the exact incidence is unknown due to the fact that symptomatic FECD is preceded by an asymptomatic phase [104]. FECD is associated with a loss of $\mathrm{Na}^{+} /$ $\mathrm{K}^{+}$-ATPase pump sites within the endothelium that eventually leads to corneal swelling $[105,106]$. FECD is associated with blurred vision, which is caused by this corneal swelling from defects in the inner corneal layer, the corneal endothelium [104, 107].

The current definitive therapy is lacking, but it includes endothelial keratoplasty; furthermore, there are currently no available nonsurgical treatments to delay or prevent the progression of the disease $[100,108]$. The disease typically presents with its clinical characteristics at some point between the 5th and 6th decades of life and can vary from macroscopic guttae producing light scattering to a decrease in visual quality, tochronic, and full thickness corneal edema [107]. Currently, the disease is considered to be a multifactorial condition, in which genetic $[109,110]$ and environmental factors, such as UV lightinduced oxidative stress $[100,108,111]$, contribute to its onset. Keratoplasty, specifically penetrating keratoplasty, has been the surgical approach of choice for many years, but currently endothelial keratoplasty such as Descemet membrane endothelial keratoplasty and Descemet-stripping automated endothelial keratoplasty are mainly performed for patients with FECD [112-114]. Currently, the primary cause of this endothelial dysfunction is unknown, but recent studies have attempted to classify changes associated with this disease.

\section{Lipidomic profiling in FECD}

The potential to identify differences in lipids associated with diseases such as FECD has been greatly improved by recent technical advances in lipidomic research such as ultra-performance liquid chromatography mass spectrometry [115]. Aqueous humor (AH) composition has been suspected to play a role in the pathophysiology of FECD [116], but the precise role remains unclear. A recent study revealed key mediators in the lipidomic profile for individuals suffering from FECD indicating the lipid composition of the AH in FECD patients differs from that of healthy subjects. The concentration of most diacylglycerophosphocholines, 1-ether, 2-acylglycerophosphocholines, eight sphingomyelins, and up to two long-chain highly unsaturated cholesteryl esters increased in the AH of FECD eyes as compared to the healthy controls [117]. These differences may be due to oxidative stress-related changes in the lipid metabolism of the corneal endothelial cells in FECD, but this is one of the first studies published concerning lipidomic changes in FECD and was performed with an exploratory scope to screen for more specific works in the future [117]. The lipidomic profile of ten AH controls with an average age of 50.8 years and eight $\mathrm{AH}$ FECD patients with an average age of 56.8 years were analyzed in the study, indicating a need for expansion to verify results [117]. Richardson et al. looked at the varying differences of protein concentration between FECD individuals and control, indicating potential markers for the disease [118], but Cabrerizo et al. was the first study to look at the lipid profile of FECD individuals. Future studies could indicate a set of markers for the disease and enable detection before there is a deficit in vision.

\section{Nonsurgical treatments for FECD}

Due to the lack of nonsurgical treatments to delay or prevent the onset of FECD, Kim et al. has sought out to screen drugs with corneal endothelial cell survival effects against two of the key physiologic markers of FECD, including oxidative stress and unfolded protein response (UPR) [119]. Multiple studies have described an association of oxidative stress-triggered UPR through various models including an endoplasmic reticulum stress-mediated apoptosis induced by cigarette smoke via a ROS dependent mechanism, an oxidative stresstriggered UPR in cell death evoked by Parkison mimetics, and the induction of UPR in a ROS through tumor necrosis factor-alpha [120-123]. Results from this study demonstrated a dose response effect of the non-steroidal anti-inflammatory drugs (NSAIDs), mefenamic acid and nimesulide, against oxidative stress and UPR in a bovine corneal endothelial cell (CEC) culture model [119]. Mefenamic acid was shown to significantly decrease oxidative stress in immortalized human corneal endothelial cells (iHCECs) exposed to $\mathrm{H}_{2} \mathrm{O}_{2}$ [119]. Nimesulide is a cyclooxygenase- 2 inhibitor and acts as an antioxidant to correct lipid peroxidation products such as malondialdehyde [124] in addition to reversing UPR through the NF- $\kappa \beta$ and pp38 kinase pathways [125]. Results indicate potential speculation for the use of NSAIDs such as mefenamic acid and nimesulide for the use as a survival factor for corneal endothelial cells undergoing oxidative stress and UPR [119].

Recent studies have also looked at the potential use of corneal regenerative medicine using cultured endothelial cells, which includes mesenchymal stem cell derived conditioned media as well as Rho-associated protein kinase inhibitors [126-128]. The development of a successful and reliable cell cultivation protocol for clinical 
application has drastically slowed the establishment of tissue engineering-based therapy for corneal endothelial dysfunction [129]. However, many studies have characterized the successful transplantation of a cultured corneal endothelial sheet into an animal model [126, 130-133]. Studies have demonstrated that RhoROCK signaling negatively regulates the integrin-mediated adhesion of monocytes, and that the inhibition of ROCK by a selective ROCK inhibitor upregulates adhesion, showing potential for enhancing the adhesion of CEC by inhibiting Rho/ROCK signaling [128, 134, 135]. Rho-ROCK signaling is involved in a multitude of cellular processes including migration, morphogenesis, cell adhesion, and cell-cycle progression through mediating cytoskeletal dynamics [136, 137].

These studies promote the potential for using ROCK inhibitor Y-27632 to enable the establishment of a cultivated-CEC-based therapy by inhibiting apoptosis, increasing the number of proliferating cells, and promoting the adhesion through a rabbit and primate corneal endothelial dysfunction model $[127,128]$. This novel strategy may ultimately provide clinicians with a potential treatment for FECD, through the use of a ROCK inhibitor using regenerative medicine [127].

\section{Future directions and challenges for Fuchs' endothelial corneal dystrophy}

Investigation into FECD has revealed a better understanding of this disease at the tissue, cellular, and molecular level. Despite substantial research, the literature still lacks consistent markers for this multifactorial disease.

Cabrerizo and co-authors have revealed the potential use of various lipids as biomarkers for the severity of disease in FECD [117], indicating promise for a better understanding of the pathophysiology of this disease. Corneal endothelial dysfunction is a substantial problem in FECD, and it is accompanied by visual disturbance which provides a major indication for corneal transplantation surgery [138]. Descemet's stripping endothelial keratoplasty is a highly effective surgical technique designed to replace corneal endothelium and overcome pathological dysfunctions of corneal endothelial tissue [139-141]. Corneal transplantation is still widely used for corneal endothelial dysfunction, but the transplantation of cultivated corneal endothelium is a new potential therapeutic strategy [127].

Studies involving lipids reveal the potential use of NSAIDs [119] for improving symptoms associated with FECD. The need for nonsurgical treatments for FECD continues to be a problem despite recent advances, indicating the need for future studies for novel lipid-based therapeutics.

\section{Concluding remarks}

The health of the ocular surface is crucial for the patient's quality of life, and it may be compromised through diseases or dystrophies. There are still limited options for lipid-based therapies, but there have been numerous advances over the past few years in novel lipid-based therapeutics for the treatments of these diseases. Lipids also show increasing promise as biomarkers for diseases such as FECD indicating increasing clinical relevance. Immunomodulation through lipids such as essential fatty acids has shown promising results as therapeutic molecules.

Despite significant progress, further studies concerning the role of lipids and the exact mechanism of action must be classified. However, lipid-based therapies provide encouraging results for the treatment of these diseases and dystrophies.

\section{Abbreviations}

DED: dry eye disease; AGE: advanced glycation end products; EPA: eicosapentaenoic acid; DHA: docosahexaenoic acid; ALA: alpha linolenic acid; PUFA: polyunsaturated fatty acid; IHMGECs: immortalized human meibomian gland epithelial cells; MMP-9: metalloproteinase-9; TBUT: tear break-up time; MGD: meibomian gland dysfunction; LPS: lipopolysaccharide; DM: diabetes mellitus; T1DM: type 1DM; T2DM: type 2DM; DPN: diabetic peripheral neuropathy; NPD1: neuroprotectin D1; FECD: Fuchs' endothelial corneal dystrophy; $\mathrm{AH}$ : aqueous humor; $\mathrm{CEC}$ : corneal endothelial cell; UPR: unfolded protein response; NF-kB: nuclear factor kappa B; LPS: lipopolysaccharide; HCFs: human corneal fibroblasts; TNF-a: tumor-necrosis factor-a; TGF- $\beta$ : transforminggrowth factor- $\beta$; IL-1 $\beta$ : interleukin-1 $\beta$; IL-6: interleukin-6; IL-8: interleukin-8; IL-1a: interleukin-1a; FAs: fatty acids; IKßa: nuclear factor of kappa light polypeptide gene enhancer in B-cells inhibitor alpha; RVs: resolvins; ROS: reactive oxygen species; L-10: interleukin-10; IL-8: interleukin-8; IL-1 $\beta$ : interleukin-1 $\beta$; NSAIDs: non-steroidal anti-inflammatory drugs.

\section{Authors' contributions}

TGR wrote the manuscript. DK reviewed/edited the manuscript. Both authors read and approved the final manuscript.

\section{Author details}

${ }^{1}$ University of Oklahoma, College of Medicine, Norman, OK, USA. ${ }^{2}$ Department of Ophthalmology/Dean McGee Eye Institute, University of Oklahoma Health Sciences Center, Oklahoma City, OK, USA.

\section{Acknowledgements}

We acknowledge the support of the NEI/DMEI Cellular Imaging Core Facility at OUHSC (P30EY021725), an unrestricted Grant (DMEI) from Research to Prevent Blindness (New York, NY USA).

\section{Competing interests}

The authors declare that they have no competing interests.

Availability of data and materials

Not applicable.

Consent for publication

Not applicable.

Ethics approval and consent to participate Not applicable.

Funding

This work was supported by R21EY025256 (NIH/NEI). 


\section{Publisher's Note}

Springer Nature remains neutral with regard to jurisdictional claims in published maps and institutional affiliations.

Received: 5 April 2017 Accepted: 26 July 2017

Published online: 01 September 2017

\section{References}

1. Marfurt CF, Murphy CJ, Florczak JL (2001) Morphology and neurochemistry of canine corneal innervation. Invest Ophthalmol Vis Sci 42(10):2242-2251

2. Wang S, Ghezzi CE, Gomes R, Pollard RE, Funderburgh JL, Kaplan DL (2017) In vitro 3D corneal tissue model with epithelium, stroma, and innervation. Biomaterials 112:1-9

3. Shaheen BS, Bakir M, Jain S (2014) Corneal nerves in health and disease. Surv Ophthalmol 59(3):263-285

4. Bron AJ, Tomlinson A, Foulks GN, Pepose JS, Baudouin C, Geerling G et al (2014) Rethinking dry eye disease: a perspective on clinical implications. Ocul Surf 12(2 Suppl):S1-S31

5. Piatigorsky J (2001) Enigma of the abundant water-soluble cytoplasmic proteins of the cornea: the "refracton" hypothesis. Cornea 20(8):853-858

6. Marfurt CF, Cox J, Deek S, Dvorscak L (2010) Anatomy of the human corneal innervation. Exp Eye Res 90(4):478-492

7. Karamichos D, Guo XQ, Hutcheon AE, Zieske JD (2010) Human cornea fibrosis: an in vitro model. Invest Ophthalmol Vis Sci 51(3):1382-1388

8. Pipparelli A, Arsenijevic Y, Thuret G, Gain P, Nicolas M, Majo F (2013) ROCK inhibitor enhances adhesion and wound healing of human corneal endothelial cells. PLoS ONE 8(4):e62095

9. Joyce NC (2012) Proliferative capacity of corneal endothelial cells. Exp Eye Res 95(1):16-23

10. Ljubimov AV, Saghizadeh M (2015) Progress in corneal wound healing Prog Retin Eye Res 49:17-45

11. Vallabh NA, Romano V, Willoughby CE (2017) Mitochondrial dysfunction and oxidative stress in corneal disease. Mitochondrion. doi:10.1016/j. mito.2017.05.009

12. Antonetti DA, Klein R, Gardner TW (2012) Diabetic retinopathy. N Engl J Med 366(13):1227-1239

13. Cheung N, Mitchell P, Wong TY (2010) Diabetic retinopathy. Lancet 376(9735):124-136

14. Dana MR, Hamrah P (2002) Role of immunity and inflammation in corneal and ocular surface disease associated with dry eye. Adv Exp Med Biol 506(Pt B):729-738

15. Thakur A, Willcox MD (2000) Contact lens wear alters the production of certain inflammatory mediators in tears. Exp Eye Res 70(3):255-259

16. Lemp MA (2008) Contact lenses and allergy. Curr Opin Allergy Clin Immunol 8(5):457-460

17. Anderson RM, Donnelly MB, Dedrick RF (1990) Measuring the attitudes of patients towards diabetes and its treatment. Patient Educ Couns 16(3):231-245

18. Cortina MS, Bazan HE (2011) Docosahexaenoic acid, protectins and dry eye. Curr Opin Clin Nutr Metab Care 14(2):132-137

19. Parmar IP, Gupta NC, Garg N, Ahluwalia BK, Khurana AK (1986) Corneal blindness - a public health problem. Indian J Public Health 30(4):193-196

20. Marsh P, Pflugfelder SC (1999) Topical nonpreserved methylprednisolone therapy for keratoconjunctivitis sicca in Sjogren syndrome Ophthalmology 106(4):811-816

21. Urban RC Jr, Cotlier E (1986) Corticosteroid-induced cataracts. Surv Ophthalmol 31(2):102-110

22. Fahy E, Subramaniam S, Brown HA, Glass CK, Merrill AH Jr, Murphy RC et al (2005) A comprehensive classification system for lipids. J Lipid Res 46(5):839-861

23. Brewitt H, Sistani F (2001) Dry eye disease: the scale of the problem. Surv Ophthalmol 45(Suppl 2):S199-S202

24. Bartlett JD, Keith MS, Sudharshan L, Snedecor SJ (2015) Associations between signs and symptoms of dry eye disease: a systematic review. Clin Ophthalmol 9:1719-1730
25. (2007) The definition and classification of dry eye disease: report of the Definition and Classification Subcommittee of the International Dry Eye WorkShop (2007). Ocul Surf 5(2):75-92

26. Sy A, O'Brien KS, Liu MP, Cuddapah PA, Acharya NR, Lietman TM et al (2015) Expert opinion in the management of aqueous Deficient Dry Eye Disease (DED). BMC Ophthalmol 15:133

27. Shapiro RL (1991) Meibomian gland dysfunction. Optom Vis Sci 68(5):390-391

28. Qiao J, Yan X (2013) Emerging treatment options for meibomian gland dysfunction. Clin Ophthalmol 7:1797-1803

29. Amano S, Inoue K (2017) Clinic-based study on Meibomian Gland Dysfunction in Japan. Invest Ophthalmol Vis Sci 58(2):1283-1287

30. Abidi A, Shukla P, Ahmad A (2016) Lifitegrast: a novel drug for treatment of dry eye disease. J Pharmacol Pharmacother 7(4):194-198

31. Sambursky R (2016) Presence or absence of ocular surface inflammation directs clinical and therapeutic management of dry eye. Clin Ophthalmol 10:2337-2343

32. Pinna A, Piccinini P, Carta F (2007) Effect of oral linoleic and gammalinolenic acid on meibomian gland dysfunction. Cornea 26(3):260-264

33. Liu Y, Kam WR, Sullivan DA (2016) Influence of omega 3 and 6 fatty acids on human meibomian gland epithelial cells. Cornea 35(8):1122-1126

34. Macsai MS (2008) The role of omega-3 dietary supplementation in blepharitis and meibomian gland dysfunction (an AOS thesis). Trans Am Ophthalmol Soc 106:336-356

35. Aragona P, Bucolo C, Spinella R, Giuffrida S, Ferreri G (2005) Systemic omega- 6 essential fatty acid treatment and pge 1 tear content in Sjogren's syndrome patients. Invest Ophthalmol Vis Sci 46(12):4474-4479

36. Miljanovic B, Trivedi KA, Dana MR, Gilbard JP, Buring JE, Schaumberg DA (2005) Relation between dietary $n-3$ and $n-6$ fatty acids and clinically diagnosed dry eye syndrome in women. Am J Clin Nutr 82(4):887-893

37. Ohtsuka Y, Okada K, Yamakawa Y, Ikuse T, Baba Y, Inage E et al (2011) Omega-3 fatty acids attenuate mucosal inflammation in premature rat pups. J Pediatr Surg 46(3):489-495

38. Pflugfelder SC, Farley W, Luo L, Chen LZ, de Paiva CS, Olmos LC et al (2005) Matrix metalloproteinase-9 knockout confers resistance to corneal epithelial barrier disruption in experimental dry eye. Am J Pathol 166(1):61-71

39. Solomon A, Dursun D, Liu Z, Xie Y, Macri A, Pflugfelder SC (2001) Pro- and anti-inflammatory forms of interleukin-1 in the tear fluid and conjunctiva of patients with dry-eye disease. Invest Ophthalmol Vis Sci 42(10):2283-2292

40. Pflugfelder SC, Jones D, Ji Z, Afonso A, Monroy D (1999) Altered cytokine balance in the tear fluid and conjunctiva of patients with Sjogren's syndrome keratoconjunctivitis sicca. Curr Eye Res 19(3):201-211

41. West-Mays JA, Strissel KJ, Sadow PM, Fini ME (1995) Competence for collagenase gene expression by tissue fibroblasts requires activation of an interleukin 1 alpha autocrine loop. Proc Natl Acad Sci USA 92(15):6768-6772

42. Trousdale MD, Zhu Z, Stevenson D, Schechter JE, Ritter T, Mircheff AK (2005) Expression of TNF inhibitor gene in the lacrimal gland promotes recovery of tear production and tear stability and reduced immunopathology in rabbits with induced autoimmune dacryoadenitis. J Autoimmune Dis 2:6

43. Rashid S, Jin YP, Ecoiffier T, Barabino S, Schaumberg DA, Dana R (2008) Topical omega-3 and omega- 6 fatty acids for treatment of dry eye. Arch Ophthalmol-Chic 126(2):219-225

44. Lewin GA, Schachter HM, Yuen D, Merchant P, Mamaladze V, Tsertsvadze A (2005) Effects of omega-3 fatty acids on child and maternal health. Evid Rep Technol Assess (Summ) 118:1-11

45. Gatell-Tortajada J (2016) Oral supplementation with a nutraceutical formulation containing omega-3 fatty acids, vitamins, minerals, and antioxidants in a large series of patients with dry eye symptoms: results of a prospective study. Clin Interv Aging 11:571

46. Epitropoulos AT, Donnenfeld ED, Shah ZA, Holland EJ, Gross M, Faulkner WJ et al (2016) Effect of oral re-esterified omega-3 nutritional supplementation on dry eyes. Cornea 35(9):1185-1191 
47. Chotikavanich S, de Paiva CS, de Li Q, Chen JJ, Bian F, Farley WJ et al (2009) Production and activity of matrix metalloproteinase-9 on the ocular surface increase in dysfunctional tear syndrome. Invest Ophthalmol Vis Sci 50(7):3203-3209

48. Sambursky R, Davitt WF 3rd, Friedberg M, Tauber S (2014) Prospective, multicenter, clinical evaluation of point-of-care matrix metalloproteinase-9 test for confirming dry eye disease. Cornea 33(8):812-818

49. Malhotra C, Singh S, Chakma P, Jain AK (2015) Effect of oral omega-3 fatty acid supplementation on contrast sensitivity in patients with moderate meibomian gland dysfunction: a prospective placebo-controlled study. Cornea 34(6):637-643

50. Deinema LA, Vingrys AJ, Wong CY, Jackson DC, Chinnery HR, Downie LE (2017) A randomized, double-masked, placebo-controlled clinical trial of two forms of omega-3 supplements for treating dry eye disease. Ophthalmology 124(1):43-52

51. Sahli E, Hosal BM, Zilelioglu G, Gulbahce R, Ustun H (2010) The effect of topical cyclosporine A on clinical findings and cytological grade of the disease in patients with dry eye. Cornea 29(12):1412-1416

52. Erdinest N, Shmueli O, Grossman Y, Ovadia H, Solomon A (2012) Anti-inflammatory effects of alpha linolenic acid on human corneal epithelial cells. Invest Ophth Vis Sci. 53(8):4396-4406

53. Serhan CN, Brain SD, Buckley CD, Gilroy DW, Haslett C, O'Neill LA et al (2007) Resolution of inflammation: state of the art, definitions and terms. FASEB J 21(2):325-332

54. Zhang MJ, Spite M (2012) Resolvins: anti-inflammatory and proresolving mediators derived from omega-3 polyunsaturated fatty acids. Annu Rev Nutr 32:203-227

55. Erdinest N, Ovadia H, Kormas R, Solomon A (2014) Anti-inflammatory effects of resolvin-D1 on human corneal epithelial cells: in vitro study. J Inflamm (Lond) 11(1):6

56. Bardsley JK, Want LL (2004) Overview of diabetes. Crit Care Nurs Q 27(2):106-112

57. Skarbez K, Priestley Y, Hoepf M, Koevary SB (2010) Comprehensive review of the effects of diabetes on ocular health. Expert Rev Ophthalmol 5(4):557-577

58. Johnson AB, Taylor R (1990) Diabetes mellitus. Postgrad Med J 66(782):1010-1024

59. Hara M (1990) Pathology of diabetes mellitus. Nihon Rinsho 48(Suppl):209-214

60. Priyadarsini S, Sarker-Nag A, Rowsey TG, Ma JX, Karamichos D (2016) Establishment of a 3D in vitro model to accelerate the development of human therapies against corneal diabetes. PLoS ONE 11(12):e0168845

61. Young MJ, Boulton AJ, MacLeod AF, Williams DR, Sonksen PH (1993) A multicentre study of the prevalence of diabetic peripheral neuropathy in the United Kingdom hospital clinic population. Diabetologia 36(2):150-154

62. Stock K (2004) Multiple cerebral aneurysms in a patient with recurrent cardiac myxomas. A case report. Interv Neuroradiol 10(4):335-340

63. Diabetic Retinopathy Clinical Research Network, Writing Committee, Aiello LP, Beck RW, Bressler NM, Browning DJ, Chalam KV, Davis M, Ferris FL 3rd, Glassman AR, Maturi RK, Stockdale CR, Topping TM (2011) Rationale for the diabetic retinopathy clinical research network treatment protocol for center-involved diabetic macular edema. Ophthalmology 118(12):e5-14. doi:10.1016/j.ophtha.2011.09.058

64. Nathan DM (2015) Diabetes: advances in diagnosis and treatment. JAMA 314(10):1052-1062

65. Nentwich MM, Ulbig MW (2015) Diabetic retinopathy-ocular complications of diabetes mellitus. World J Diabetes 6(3):489-499

66. Coppey LJ, Davidson EP, Obrosov A, Yorek MA (2015) Enriching the diet with menhaden oil improves peripheral neuropathy in streptozotocininduced type 1 diabetic rats. J Neurophysiol 113(3):701-708

67. Coppey LJ, Davidson EP, Dunlap JA, Lund DD, Yorek MA (2000) Slowing of motor nerve conduction velocity in streptozotocin-induced diabetic rats is preceded by impaired vasodilation in arterioles that overlie the sciatic nerve. Int J Exp Diabetes Res 1(2):131-143

68. Shevalye H, Yorek MS, Coppey LJ, Holmes A, Harper MM, Kardon RH et al (2015) Effect of enriching the diet with menhaden oil or daily treatment with resolvin D1 on neuropathy in a mouse model of type 2 diabetes. J Neurophysiol 114(1):199-208

69. Lee JE, Sun Y, Gjorstrup P, Pearlman E (2015) Inhibition of corneal inflammation by the resolvin E1. Invest Ophth Vis Sci 56(4):2728-2736
70. Yorek MS, Coppey LJ, Shevalye H, Obrosov A, Kardon RH, Yorek MA (2016) Effect of treatment with salsalate, menhaden oil, combination of salsalate and menhaden oil, or resolvin D1 of C57BI/6J type 1 diabetic mouse on neuropathic endpoints. J Nutr Metab 2016:5905891

71. Higgs GA, Salmon JA, Henderson B, Vane JR (1987) Pharmacokinetics of aspirin and salicylate in relation to inhibition of arachidonate cyclooxygenase and antiinflammatory activity. Proc Natl Acad Sci USA 84(5):1417-1420

72. Davidson EP, Holmes A, Coppey LJ, Yorek MA (2015) Effect of combination therapy consisting of enalapril, alpha-lipoic acid, and menhaden oi on diabetic neuropathy in a high fat/low dose streptozotocin treated rat. Eur J Pharmacol 765:258-267

73. Diau GY, Hsieh AT, Sarkadi-Nagy EA, Wijendran V, Nathanielsz PW, Brenna JT (2005) The influence of long chain polyunsaturate supplementation on docosahexaenoic acid and arachidonic acid in baboon neonate central nervous system. BMC Med 3:11

74. Greiner RC, Winter J, Nathanielsz PW, Brenna JT (1997) Brain docosahexaenoate accretion in fetal baboons: bioequivalence of dietary alphalinolenic and docosahexaenoic acids. Pediatr Res 42(6):826-834

75. Anderson RE, Maude MB, McClellan M, Matthes MT, Yasumura D, LaVail MM (2002) Low docosahexaenoic acid levels in rod outer segments of rats with $\mathrm{P} 23 \mathrm{H}$ and S334ter rhodopsin mutations. Mol Vis 8:351-358

76. Bicknell IR, Darrow R, Barsalou L, Fliesler SJ, Organisciak DT (2002) Alterations in retinal rod outer segment fatty acids and light-damage susceptibility in $\mathrm{P} 23 \mathrm{H}$ rats. Mol Vis 8:333-340

77. Organisciak DT, Darrow RM, Jiang YL, Blanks JC (1996) Retinal light damage in rats with altered levels of rod outer segment docosahexaenoate. Invest Ophthalmol Vis Sci 37(11):2243-2257

78. Moriguchi T, Salem N Jr (2003) Recovery of brain docosahexaenoate leads to recovery of spatial task performance. J Neurochem 87(2):297-309

79. Litman BJ, Niu SL, Polozova A, Mitchell DC (2001) The role of docosahexaenoic acid containing phospholipids in modulating $\mathrm{G}$ proteincoupled signaling pathways: visual transduction. J Mol Neurosci 16(2-3):237-242 (discussion 79-84)

80. Kim HY, Akbar M, Lau A, Edsall L (2000) Inhibition of neuronal apoptosis by docosahexaenoic acid (22:6n-3). Role of phosphatidylserine in antiapoptotic effect. J Biol Chem 275(45):35215-35223

81. Serhan CN, Dalli J, Colas RA, Winkler JW, Chiang N (2015) Protectins and maresins: new pro-resolving families of mediators in acute inflammation and resolution bioactive metabolome. Biochim Biophys Acta 1851(4):397-413

82. Serhan CN, Chiang N (2013) Resolution phase lipid mediators of inflammation: agonists of resolution. Curr Opin Pharmacol 13(4):632-640

83. Liu M, Boussetta T, Makni-Maalej K, Fay M, Driss F, El-Benna J et al (2014) Protectin DX, a double lipoxygenase product of DHA, inhibits both ROS production in human neutrophils and cyclooxygenase activities. Lipids 49(1):49-57

84. Calandria JM, Marcheselli VL, Mukherjee PK, Uddin J, Winkler JW, Petasis NA et al (2009) Selective survival rescue in 15-lipoxygenase-1-deficient retinal pigment epithelial cells by the novel docosahexaenoic acidderived mediator, neuroprotectin D1.J Biol Chem 284(26):17877-17882

85. Bazan NG (2006) Cell survival matters: docosahexaenoic acid signaling, neuroprotection and photoreceptors. Trends Neurosci 29(5):263-271

86. Serhan CN, Dalli J, Karamnov S, Choi A, Park CK, Xu ZZ et al (2012) Macrophage proresolving mediator maresin 1 stimulates tissue regeneration and controls pain. FASEB J 26(4):1755-1765

87. Chiang N, Fredman G, Backhed F, Oh SF, Vickery T, Schmidt BA et al (2012) Infection regulates pro-resolving mediators that lower antibiotic requirements. Nature 484(7395):524-528

88. Cortina MS, He J, Russ T, Bazan NG, Bazan HE (2013) Neuroprotectin D1 restores corneal nerve integrity and function after damage from experimental surgery. Invest Ophthalmol Vis Sci 54(6):4109-4116

89. Li Z, Burns AR, Han L, Rumbaut RE, Smith CW (2011) IL-17 and VEGF are necessary for efficient corneal nerve regeneration. Am J Pathol 178(3):1106-1116

90. Su DH, Wong TY, Wong WL, Saw SM, Tan DT, Shen SY et al (2008) Diabetes, hyperglycemia, and central corneal thickness: the Singapore Malay Eye Study. Ophthalmology 115(6):964-968

91. Lee JS, Oum BS, Choi HY, Lee JE, Cho BM (2006) Differences in corneal thickness and corneal endothelium related to duration in diabetes. Eye (Lond) 20(3):315-318 
92. Schultz RO, Van Horn DL, Peters MA, Klewin KM, Schutten WH (1981) Diabetic keratopathy. Trans Am Ophthalmol Soc 79:180-199

93. Schultz RO, Peters MA, Sobocinski K, Nassif K, Schultz KJ (1983) Diabetic keratopathy as a manifestation of peripheral neuropathy. Am J Ophthalmol 96(3):368-371

94. Araki K, Ohashi Y, Kinoshita S, Hayashi K, Kuwayama Y, Tano Y (1994) Epithelial wound healing in the denervated cornea. Curr Eye Res 13(3):203-211

95. Baker KS, Anderson SC, Romanowski EG, Thoft RA, SundarRaj N (1993) Trigeminal ganglion neurons affect corneal epithelial phenotype. Influence on type VII collagen expression in vitro. Invest Ophthalmol Vis Sci 34(1):137-144

96. Saini JS, Khandalavla B (1995) Corneal epithelial fragility in diabetes mellitus. Can J Ophthalmol 30(3):142-146

97. Gekka M, Miyata K, Nagai Y, Nemoto S, Sameshima T, Tanabe T et al (2004) Corneal epithelial barrier function in diabetic patients. Cornea 23(1):35-37

98. Gobbels M, Spitznas M, Oldendoerp J (1989) Impairment of corneal epithelial barrier function in diabetics. Graefes Arch Clin Exp Ophthalmol 227(2):142-144

99. Borderie VM, Baudrimont M, Vallee A, Ereau TL, Gray F, Laroche L (2000) Corneal endothelial cell apoptosis in patients with Fuchs' dystrophy. Invest Ophthalmol Vis Sci 41(9):2501-2505

100. Jurkunas UV, Bitar MS, Funaki T, Azizi B (2010) Evidence of oxidative stress in the pathogenesis of fuchs endothelial corneal dystrophy. Am J Pathol 177(5):2278-2289

101. Czarny P, Kasprzak E, Wielgorski M, Udziela M, Markiewicz B, Blasiak J et al (2013) DNA damage and repair in Fuchs endothelial corneal dystrophy. Mol Biol Rep 40(4):2977-2983

102. Stipanitzova H, Gerinec A (2003) Corneal dystrophies. Cesk Slov Oftalmol 59(5):359-367

103. Bahn CF, Falls HF, Varley GA, Meyer RF, Edelhauser HF, Bourne WM (1984) Classification of corneal endothelial disorders based on neural crest origin. Ophthalmology 91(6):558-563

104. Elhalis H, Azizi B, Jurkunas UV (2010) Fuchs endothelial corneal dystrophy. Ocul Surf 8(4):173-184

105. Mandell RB, Polse KA, Brand RJ, Vastine D, Demartini D, Flom R (1989) Corneal hydration control in Fuchs' dystrophy. Invest Ophthalmol Vis Sci 30(5):845-852

106. McCartney MD, Wood TO, McLaughlin BJ (1989) Moderate Fuchs' endothelial dystrophy ATPase pump site density. Invest Ophthalmol Vis Sci 30(7):1560-1564

107. Zhang J, Patel DV (2015) The pathophysiology of Fuchs' endothelial dystrophy - a review of molecular and cellular insights. Exp Eye Res 130:97-105

108. Azizi B, Ziaei A, Fuchsluger T, Schmedt T, Chen Y, Jurkunas UV (2011) p53-regulated increase in oxidative-stress-induced apoptosis in Fuchs endothelial corneal dystrophy: a native tissue model. Invest Ophthalmol Vis Sci 52(13):9291-9297

109. Biswas S, Munier FL, Yardley J, Hart-Holden N, Perveen R, Cousin P et al (2001) Missense mutations in COL8A2, the gene encoding the alpha2 chain of type VIII collagen, cause two forms of corneal endothelial dystrophy. Hum Mol Genet 10(21):2415-2423

110. Gottsch JD, Zhang C, Sundin OH, Bell WR, Stark WJ, Green WR (2005) Fuchs corneal dystrophy: aberrant collagen distribution in an L450W mutant of the COL8A2 gene. Invest Ophthalmol Vis Sci 46(12):4504-4511

111. Karamichos D, Hutcheon AE, Rich CB, Trinkaus-Randall V, Asara JM Zieske JD (2014) In vitro model suggests oxidative stress involved in keratoconus disease. Sci Rep 4:4608

112. Price MO, Giebel AW, Fairchild KM, Price FW Jr (2009) Descemet's membrane endothelial keratoplasty: prospective multicenter study of visual and refractive outcomes and endothelial survival. Ophthalmology 116(12):2361-2368

113. Price MO, Price FW (2007) Descemet's stripping endothelial keratoplasty. Curr Opin Ophthalmol 18(4):290-294

114. Anijeet DR, Rachdan D, Shah S (2012) Visual improvement after corneal endothelial transplantation: are we seeing better? Br J Ophthalmol 96(3):309-310

115. Nygren H, Seppanen-Laakso T, Castillo S, Hyotylainen T, Oresic M (2011) Liquid chromatography-mass spectrometry (LC-MS)-based lipidomics for studies of body fluids and tissues. Methods Mol Biol 708:247-257
116. Wilson SE, Bourne WM, Maguire LJ, Rahhal FM, Ribaudo RK, Kreutzer DL et al (1989) Aqueous humor composition in Fuchs' dystrophy. Invest Ophthalmol Vis Sci 30(3):449-453

117. Cabrerizo JUJA, de Mora MC, Vecino E, Melles G (2017) Changes in lipidomic profile of aqueous humor in Fuchs endothelial corneal dystrophy. Invest Ophth Vis Sci 56(7):1177

118. Richardson MR, Segu ZM, Price MO, Lai X, Witzmann FA, Mechref Y et al (2010) Alterations in the aqueous humor proteome in patients with Fuchs endothelial corneal dystrophy. Mol Vis 16:2376-2383

119. Kim EC, Toyono T, Berlinicke CA, Zack DJ, Jurkunas U, Usui T et al (2017) Screening and characterization of drugs that protect corneal endothelial cells against unfolded protein response and oxidative stress. Invest Ophthalmol Vis Sci 58(2):892-900

120. Holtz WA, Turetzky JM, Jong YJ, O'Malley KL (2006) Oxidative stresstriggered unfolded protein response is upstream of intrinsic cell death evoked by parkinsonian mimetics. J Neurochem 99(1):54-69

121. Xue X, Piao JH, Nakajima A, Sakon-Komazawa S, Kojima Y, Mori Ket al (2005) Tumor necrosis factor alpha (TNFalpha) induces the unfolded protein response (UPR) in a reactive oxygen species (ROS)-dependent fashion, and the UPR counteracts ROS accumulation by TNFalpha. J Biol Chem 280(40):33917-33925

122. Tagawa Y, Hiramatsu N, Kasai A, Hayakawa K, Okamura M, Yao J et al (2008) Induction of apoptosis by cigarette smoke via ROS-dependent endoplasmic reticulum stress and CCAAT/enhancer-binding proteinhomologous protein (CHOP). Free Radic Biol Med 45(1):50-59

123. Huang SS, Cheng H, Tang CM, Nien MW, Huang YS, Lee IH et al (2013) Anti-oxidative, anti-apoptotic, and pro-angiogenic effects mediate functional improvement by sonic hedgehog against focal cerebral ischemia in rats. Exp Neurol 247:680-688

124. Yesilot S, Ozer MK, Bayram D, Oncu M, Karabacak HI, Cicek E (2010) Effects of aspirin and nimesulide on tissue damage in diabetic rats. Cytokine 52(3):163-167

125. Hung JH, Su IJ, Lei HY, Wang HC, Lin WC, Chang WT et al (2004) Endoplasmic reticulum stress stimulates the expression of cyclooxygenase-2 through activation of NF-kappaB and pp38 mitogen-activated protein kinase. J Biol Chem 279(45):46384-46392

126. Okumura N, Kinoshita S, Koizumi N (2014) Cell-based approach for treatment of corneal endothelial dysfunction. Cornea 33(Suppl 11):S37-S41

127. Okumura N, Koizumi N, Ueno M, Sakamoto Y, Takahashi H, Tsuchiya H et al (2012) ROCK inhibitor converts corneal endothelial cells into a phenotype capable of regenerating in vivo endothelial tissue. Am J Pathol 181(1):268-277

128. Okumura N, Ueno M, Koizumi N, Sakamoto Y, Hirata K, Hamuro J et al (2009) Enhancement on primate corneal endothelial cell survival in vitro by a ROCK inhibitor. Invest Ophthalmol Vis Sci 50(8):3680-3687

129. Peh GS, Beuerman RW, Colman A, Tan DT, Mehta JS (2011) Human corneal endothelial cell expansion for corneal endothelium transplantation: an overview. Transplantation 91(8):811-819

130. Ishino Y, Sano Y, Nakamura T, Connon CJ, Rigby H, Fullwood NJ et al (2004) Amniotic membrane as a carrier for cultivated human corneal endothelial cell transplantation. Invest Ophthalmol Vis Sci 45(3):800-806

131. Mimura T, Yamagami S, Yokoo S, Usui T, Tanaka K, Hattori S et al (2004) Cultured human corneal endothelial cell transplantation with a collagen sheet in a rabbit model. Invest Ophthalmol Vis Sci 45(9):2992-2997

132. Sumide T, Nishida $K$, Yamato M, Ide T, Hayashida Y, Watanabe $K$ et al (2006) Functional human corneal endothelial cell sheets harvested from temperature-responsive culture surfaces. FASEB J 20(2):392-394

133. Koizumi N, Sakamoto Y, Okumura N, Okahara N, Tsuchiya H, Torii R et al (2007) Cultivated corneal endothelial cell sheet transplantation in a primate model. Invest Ophthalmol Vis Sci 48(10):4519-4526

134. Worthylake RA, Lemoine S, Watson JM, Burridge K (2001) RhoA is required for monocyte tail retraction during transendothelial migration. J Cell Biol 154(1):147-160

135. Worthylake RA, Burridge K (2003) RhoA and ROCK promote migration by limiting membrane protrusions. J Biol Chem 278(15):13578-13584

136. Hall A (1998) Rho GTPases and the actin cytoskeleton. Science 279(5350):509-514 
137. Narumiya S, Tanji M, Ishizaki T (2009) Rho signaling, ROCK and mDia1, in transformation, metastasis and invasion. Cancer Metastasis Rev 28(1-2):65-76

138. Darlington JK, Adrean SD, Schwab IR (2006) Trends of penetrating keratoplasty in the United States from 1980 to 2004. Ophthalmology 113(12):2171-2175

139. Chen ES, Shamie N, Terry MA (2008) Descemet-stripping endothelia keratoplasty: improvement in vision following replacement of a healthy endothelial graft. J Cataract Refract Surg 34(6):1044-1046
140. Anshu A, Price MO, Price FW Jr (2013) Descemet stripping automated endothelial keratoplasty for Fuchs endothelial dystrophy-influence of graft diameter on endothelial cell loss. Cornea 32(1):5-8

141. Price FW Jr, Price MO (2005) Descemet's stripping with endothelial keratoplasty in 50 eyes: a refractive neutral corneal transplant. J Refract Surg 21(4):339-345

\section{Submit your manuscript to a SpringerOpen ${ }^{\circ}$ journal and benefit from:}

- Convenient online submission

- Rigorous peer review

- Open access: articles freely available online

- High visibility within the field

Retaining the copyright to your article

Submit your next manuscript at springeropen.com 